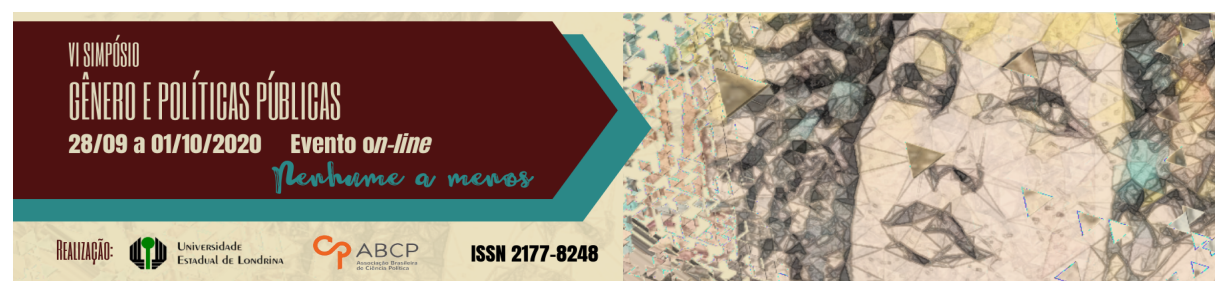

\title{
Pró-feminismo e não violência contra a mulher nas letras do Emicida
}

\author{
Jamilly Nicácio Nicolete; Carol Freitas
}

\section{Resumo}

Recentemente o machismo presente nas letras de músicas se tornou tema para um importante debate sobre a percepção da incitação à violência, à manutenção dos estereótipos de gênero, apologia ao estupro, assédio sexual e reprodução das desigualdades. São exemplos, projetos como o Música Machista Popular Brasileira (MMPB), uma clara referência à MPB (Música Popular Brasileira), criado em 2018 e estudos como de Claro e Pereira, que analisam o Sexismo nas letras de rap: a sedimentação do machismo pela música; o de Silva e Lage, sobre Músicas que violentam a mulher: representações machistas nas letras do forró estilizado ou o artigo escrito por Verunschk, que analisa a identidade e machismo no forró pé de serra e no forró eletrônico. No MMPB, letras de Funks, Sertanejo (universitário) e até MPB tiveram seus trechos analisados e até reescritos. No entanto, existem músicos que escancaram as desigualdades em suas letras, que reivindicam lugar de fala e, que fazem um movimento pró-feminista, tema pouco tratado em textos e eventos que permeiam os estudos de gênero, mas que apresenta uma importante marca de diferenciação entre homem feminista e prófeminismo, visto que um movimento idealizado e protagonizado por mulheres não precisa (e não pode) ter homens como figura central. O objetivo principal deste artigo, que lançou mão de diferentes referências bibliográficas relativas aos estudos de gênero, é refletir acerca das letras das músicas do rapper, cantor e compositor brasileiro, Emicida, refletindo sobre gênero enquanto uma perspectiva bidimensional fraseriana. Buscamos, ainda, identificar as consequências negativas desse machismo musical para a formação das futuras gerações, uma vez que mantém a percepção patriarcal e exclui de um espaço acessível à população o debate sobre temas feministas. Músicas como Mãe, Ooorra, e as canções do álbum mais recente do artista, AmarElo, problematizam a assimetria entre os gêneros no Brasil, temas ligados à desigualdade racial, bem como a postura de resistência frente ao 
momento em que os direitos humanos no país estão ameaçados.

A trajetória das mulheres em nossa sociedade é marcada por mecanismos de exclusão. A deturpação de sua imagem, a luta por garantia de direitos e a constante perda dos mesmo, a violação de princípios morais, a violência e a misoginia, reforçam ou são reforçadas por uma representação errônea e limitante das mulheres. Tal conduta se materializou principalmente por meio dos mecanismos de subalternização, silenciamento e opressão que colocaram as mulheres à margem da sociedade e das políticas públicas.

A lógica patriarcal e seus mecanismos propulsores das variadas formas de violência sofrida pelas mulheres pressupõe entender as raízes históricas que remontam esse percurso de transgressões. Nesse sentido, para compreender o conceito de violência nos apoiamos no conceito apresentado por Saffioti (2004, p.76), que entende por violência todo e qualquer agenciamento capaz de violá-los. Às mulheres caberia apenas espaços subalternos, menos técnicos e mais ligados ao cuidar e, consequentemente, de menor prestígio social, sendo, desde sempre, consideradas incapazes de ocupar espaços que necessitem da tomada de decisões.

Para Teles e Melo (2003, p. 18), o conceito de violência de gênero deve ser entendido como uma relação de poder de dominação e submissão da mulher. As autoras demonstram que os papéis impostos às mulheres e aos homens, consolidados ao longo da história e reforçados pelo patriarcado e sua ideologia, induzem relações violentas entre os sexos e indica que a prática desse tipo de violência não é fruto da natureza, mas sim do processo de socialização das pessoas.

Segundo o IBGE (PNAD, 2017) as brasileiras entram no mercado de trabalho na mesma proporção que os homens, representando 55\% dos e das analistas júnior. No entanto, quanto mais sênior a posição, menor a representação delas. Além disso, o salário 
das mulheres brasileiras com filhos é, em média, 35\% menor que o das que não têm filhos, evidenciando o impacto da maternidade na renda feminina. O levantamento foi feito pelo Instituto Brasileiro de Economia da FGV Rio.

Para Saffioti (2004, p. 35) as mulheres são "amputadas", sobretudo no desenvolvimento e uso da razão e no exercício do poder. Elas são socializadas para desenvolver comportamentos dóceis, cordatos, apaziguadores. Os homens, ao contrário, são estimulados a desenvolver condutas agressivas, perigosas, que revelam força e coragem. A reprodução dos rótulos reducionistas fez com que as mulheres incorporassem o discurso da passividade e da subordinação, base do domínio machista (RODRIGUES, 2008). As relações assimétricas e hierarquizadas entre homens e mulheres constitui a base da violência contra a mulher.

A indústria da música é um espaço de capital cultural e poder. Para além da disputa MPB, pretensamente culta e elitizada, versus, funk, degradante e sexualizada, temos as letras de músicas que desde o início dos anos 1920 performatizam uma experiência subalternizada da mulher. Mulher indigesta, de Noel Rosa, que merece um tijolo na testa; Geni e o Zepelim, de Chico Buarque, mulher feita para apanhar, boa de cuspir porque dá para qualquer um, ou mesmo os sertanejos, universitários ou não, que sugerem, como é o caso da dupla Bruno e Marrone, e sua canção que remete a romantização de um relacionamento claramente abusivo "Ou a gente se assume/ Ou acaba morrendo de tanto ciúme/ Vou te amarrar na minha cama/ Só vai fazer amor comigo/ Eu te quero e preciso/ Só junto de você/ A minha vida faz sentido" ou em casos menos óbvios, com letras que parecem carinhosas, mas aprofundam a falta de autonomia da mulher em seus relacionamento, como é o caso de Vidinha de balada, de Henrique e Juliano, em que o homem impõe sua vontade, dizendo: "Vai namorar comigo sim, Vai por mim igual nós dois não tem".

Em 2018 a jornalista Juliana Costa, da Folha de Pernambuco, publicou uma matéria que evidencia como a misoginia e o machismo 
estão incutidos nos mais variados estilos musicais desde sempre. A publicação começa refletindo sobre a época do carnaval e o quanto nesse período as discussões sobre assédio e violência aumentam, devido o número de crimes sexuais aumentarem consideravelmente nessa época do ano.

A gravidade dos casos encontra justificativa em tentativas absurdas de minimizar a ação violenta com a típica frase "Mas é carnaval..." como se o fato de ser época de festa e folia autorizasse as pessoas a agirem de forma criminosa e descabida. Como se não bastassem as atitudes machistas surgem músicas com letras para dizer o mínimo, duvidosas, que contribuem em muito para a propagação das mais diferentes formas de violência.

Músicas que trazem claramente apologia ao estupro e a violência contra a mulher viram hits entre os mais tocados nacionalmente e ganham popularidade, sendo repetidos sem qualquer pudor por homens e mulheres, em meio a alguns gritos abafados de grupos que são atacados justamente por se indignarem.

Porém, alguns protestos não passaram despercebidos e diante da ampla divulgação da música Surubinha de leve, do MC Diguinho, uma adolescente tirou uma foto maquiada de maneira a parecer ter sofrido uma agressão doméstica, segurando uma placa com dizeres que afirmavam o quanto uma música como aquela ajudavam a cultura do estupro a se estender. A foto viralizou, realizaram-se petições jurídicas e a música foi retirada do Spotify. Mas nem por isso houve ou deva haver comemoração, pois a música não deixou de ser tocada nem de render muito dinheiro ao artista.

E desde a época de Amélia que era a mulher de verdade, de Ataulfo Alves, vivenciamos experiências como essas, que precisam ser cada vez mais combatidas. Até músicas infantis como Maria Chiquinha, eternizada por Sandy e Junior, da década de 1990 não conseguiram abandonar a misoginia e acabaram reforçando a violência contra a mulher. Isso mostra que não existe um único estilo de música que 
traga machismo e violência em suas letras, todos devem passar por análises e reflexão a luz da igualdade entre os gêneros e em prol do enfrentamento da violência contra as mulheres. No retorno da dupla, para uma turnê comemorativa, Júnior afirmou, em Fortaleza, "O resto? Para com isso, isso aí não é mais aceitável, não são mais os anos 90. Não vou fazer nada com o resto, deixa em paz a Maria Chiquinha. A Maria Chiquinha faz o que ela quiser no mato. Não é muito melhor?", numa clara ressignificação. O cantor foi bastante aplaudido.

Estamos vivendo grandes mudanças, mas há muito ainda a ser realizado, transformar nossa linguagem é um caminho, árduo, mas seguro, de viabilizar a busca por uma sociedade menos patriarcal e igualitária.

\section{Gênero e Música}

Acerca da ausência de uma real preocupação em como as mulheres têm sido retratadas nas letras musicais, vale destacar um estudo realizado na Áustria, por um doutor em Psicologia Social, que além de pesquisador atua como professor na Universidade de Innsbruck, Tobias Greitemeyer.

O grande questionamento é o quanto letras misóginas, machistas, com mensagens agressivas podem influenciar um ouvinte a ser ainda mais violento. Uma pergunta foi lançada pela pesquisa: quando o tema é machismo, o quanto a vida imita a canção? $\mathrm{Na}$ pesquisa específica do professor supracitado, publicada pelo site do G1 no dia 6 de agosto de 2016, participaram cerca de 170 jovens, que durante os estudos ouviam músicas de grupos como Eminnem e Offspring, sem saber o tema da investigação acadêmica, apenas ouviam as músicas e realizam tarefas ao mesmo tempo.

Entre as questões aleatórias que foram respondendo na pesquisa, algumas eram acerca de gêneros, como atributos relacionados a homens e mulheres, assim como o suposto direito de 
um homem se vingar de uma mulher no caso de uma traição. O pesquisador percebeu que os homens tendiam a marcar mais atributos negativos para as mulheres e expressar mais desejo de vingança quando tinham ouvido músicas com conteúdo machista. Já os homens que escutavam músicas com letras neutras, sem conteúdo violento, expressavam claramente mais carinho com as mulheres e menos desejo de vingança.

Sendo assim, o estudo chegou à conclusão de que letras machistas podem claramente reforçar a tendência agressiva de um homem contra uma mulher. Uma outra parte da pesquisa usou pimenta para indicar esse comportamento mais agressivo dos homens que participaram dos estudos.

Entre as tarefas aleatórias propostas durante a pesquisa foi pedido que eles temperassem o lanche que seria servido a uma mulher, eles eram inclusive informados que a mulher que receberia o lanche não era muito fã de pimenta e para constatação do professor orientador da enquete aqueles que ouviam mais frequentemente as músicas machistas, preparavam o lanche mais picante para ser oferecido a mulher em questão. A pimenta serviu como um reforço a conclusão dessa pesquisa austríaca, letra que expõe conteúdo machista e violento incentiva visivelmente uma violência real contra a mulher.

Se músicas que trazem letras machistas e violentas estimulam a violência contra a mulher, conforme temos evidenciado através de alguns estudos recentes, procurar incentivar o contrário, expondo as pessoas a ouvirem conteúdos de combate e esse tipo de comportamento também deve funcionar.

É necessário trabalhar com a prevenção da violência de gênero, fica evidente que tratar só do instrumento punitivo da lei Maria da Penha, levando em consideração o Brasil, não é e jamais será suficiente.

Seguindo nossa avaliação sobre a influência da música que contenha conteúdos machistas na vida em sociedade, em especial, no 
rap e hip-hop, desde que surgiram mostram- se como espaço em que predomina o universo masculino.

Mais do que um espaço masculino traz um problema grave que é a repercussão constante do machismo e do sexismo que tanto nos separam uns dos outros, gerando conflitos, violência e tragédias recorrentes.

Recentemente, em um evento sobre Mulher e Sociedade, no ano de 2019, estudantes de comunicação, da Universidade Estadual do Centro-Oeste, como Paula Cabrera Claro e sua parceira de pesquisa Ariane Carla Pereira, analisaram o chamado sexismo, nas letras de rap da música brasileira.

É inegável e de extrema necessidade dizer que a cultura hip hop em geral tem um papel fundamental nas denúncias sobre desigualdades e a urgência em se dar visibilidade para as minorias. Muito mais do que entretenimento o hip hop tornou um instrumento político de grande repercussão mundial.

No entanto, embora seja uma ferramenta poderosa que trata de representatividade das periferias acabou não englobando de fato a todos, ou melhor, a todas as minorias. Isto porque em suas letras perpetuam-se preconceitos e estereótipos criados acerca das mulheres, como palavras que indiquem características de promiscuidade, submissão ou interesseira.

Assim o feminino segue sendo desvalorizado na sociedade brasileira, por músicas, cantores e compositores de renome no universo musical, como o grupo dos Racionais, Facção Central, Gabriel (o pensador) e o próprio Emicida, tão engajado em causas sociais. Em contrapartida temos presenciado a luta das mulheres por conquistar espaço na música, no palco, nas composições, no entretenimento e em especial na música como ferramenta política de combate a misoginia e a violência contra a mulher.

Ainda na década de 1990 surgiria Lady Rap com a música 
Codinome Feminista e mais recentemente Dina Di com a letra Meu filho, minhas regras, além da Lívia Cruz com a música intitulada $E u$ tava lá. As mulheres têm buscado e proposto reflexão acerca da representação da mulher na música e no Rap não tem sido diferente.

As letras das músicas não só podem como devem ser uma bandeira pela igualdade entre os gêneros. Justamente por isso quando a letra de uma música reforça a ideia da mulher como objeto sexual estamos na contramão dessas conquistas por igualdade, respeito e liberdade tão almejados pelo movimento feminista.

Em 2013 quando o rapper paulistano Emicida lançou um álbum independente e uma das faixas trouxe a música Trepadeira, com trechos que objetificam a mulher dentro desses estereótipo de objeto sexual, além de levar a inúmeras interpretações quando menciona que mulher " biscate" deve tomar uma surra de espada de São Jorge, uma grande polêmica surgiu e enormes discussões de lá para cá tem ocorrido, questionando se algumas das músicas do rapper que tem uma voz que representa tanto as minorias, realmente incentivam o machismo, a misoginia e a violência.

No site Geledés, a jornalista e blogueira Nádia Lapa trouxe à tona essa questão sobre as letras das músicas do Emicida, mencionando justamente a música Trepadeira. No artigo a jornalista diz que a polêmica dividiu opiniões como é comum de acontecer, mas que a postura de Emicida foi questionável e decepcionante para grande parte das feministas porque o mesmo não reconheceu sequer que pudesse ter cometido um equívoco e publicou uma nota apenas justificando e defendendo a letra da música que produziu. $\mathrm{O}$ artigo obviamente não culpabiliza Emicida pela misoginia e machismo no mundo, mas quer imputar ao mesmo responsabilidade haja vista o poder de voz e influência que o rapper possui na sociedade hoje, devido a grande visibilidade que tem.

O filósofo alemão Karl Jaspers já em 1946, em seu livro A culpa alemã, evidenciava a necessidade de se diferenciar os conceitos de 
culpa e responsabilidade, sendo a culpa característica específica de quem diretamente comete algum ato danoso a outrem enquanto responsabilidade todos nós temos quando podendo agir em favor de alguém ou contra uma injustiça, utilizando nossa voz e endossando nossa postura escolhemos não nos posicionar ou até mesmo agimos como propagadores de algum tipo de violência, seja ela simbólica ou física. Isso se aplica perfeitamente ao caso em questão.

Na letra trepadeira fica muito claro o recado de que não se deve cuidar ou proteger uma mulher "trepadeira", o que reforça um discurso desumanizante, que restringe ao feminino somente à vida sexual, causando desconfiança a respeito de sua dignidade conforme o número de parceiros que ela tenha escolhido ou não ter.

O destaque do artigo mencionado foi para a tentativa do rapper em se justificar acerca da letra da música comparando-a a uma outra canção composta pelo mesmo num disco anterior, intitulada Vacilão, na qual o personagem não tratava bem sua mulher, a traía com outras e terminava na solidão. Mas basta observar que chamar alguém de vacilão não traz incutido um julgamento de caráter, pautado na vida sexual do suposto "vacilão", enquanto o castigo do mesmo é a solidão e o da "trepadeira" é tomar uma surra. Cabe a reflexão. Isso diz muito mais do que imaginamos acerca da sexualidade e liberdade da mulher, por isso, é uma análise de gênero e seu papel na sociedade.

Uma gama imensa de músicas traz a mulher não somente como um objeto sexual, mas como aquela que deve satisfazer as vontades do homem para não merecer uma agressão, daí ser ainda mais grave quando uma letra que menciona a mulher e a subjetiva e objetifica dessa forma vem justo de um rapper que ganhou tanta repercussão no país e no mundo, como é o caso do Emicida.

No caso do funk, é inegável seu papel emancipatório como prática cultural, no entanto, muitas letras desse estilo musical acabam banalizando a violência sexual, expondo as relações conflituosas de gênero que ainda persistem na sociedade. 
A análise das mais variadas músicas de funk nos mostram a naturalização da violência sexual, através da culpabilização da vítima, da erotização de meninas, até mesmo exaltando o estupro coletivo. É um cenário assustador e preocupante. Não foram raras as vezes em que crimes de estupro coletivo ocorreram e foram amplamente divulgados pela mídia. Mas o mais grave é que os próprios agressores passaram de uns tempos para cá a postarem os vídeos em que executam esses crimes bárbaros, sem o menor pudor, o que repercute na mídias sociais através de uma nomenclatura específica: violência ostentação.

Essa expressão por meio da qual referem-se às ações desses criminosos surgiu como uma referência ao dito "funk ostentação", que estimula a idolatria ao consumo e a exposição de bem materiais de marca. O que assusta é a referência a violência como representação de poder, que resulta em agressões, encontrando, na chamada cultura do estupro, terreno fértil para prosperar. E tão questionável em tempos de um neoliberalismo tão cruel e uma meritocracia tão falaciosa.

As agressões começam e passam pela linguagem, por isso, para o combate da violência em todos as esferas, é necessário compreender a ligação entre o cotidiano social e os discursos propagados pelas diferentes tecnologias sociais.

O que precisa ficar claro é que não se defende a inexistência de estilos os mais variados nem tão pouco a censura dos meios de comunicação o que fere a democracia, propõe-se regulamentar sua abordagem, questionando práticas e discursos machistas, misóginos, que inferiorizem e "coisifiquem" a mulher.

Logo no início da letra de uma das músicas mais tocadas nas redes do Brasil, Baile de favela, vislumbramos a exploração de relações sexuais rodeadas de violência de gênero. Não é questão de discutir o que é moral, mas de ter consciência dos riscos aos quais todos ficamos expostos diante da perpetuação de discursos violentos que tem sido banalizados e tratados como inofensivos. 
E aprofundando ainda mais o assunto, compreender a relação que existe entre erotismo e violência nas letras de funk, requer, principalmente o entendimento da interseccionalidade que existe entre questões de raça, classe e gênero. É fundamental entender que muitas vezes a mulher não é somente vítima da violência de gênero, mas está privada de qualquer proteção social que pudesse sequer lhe garantir o "status de vítima".

Existem desigualdade estruturais que naturalmente potencializam as mais diversas formas de violência, ter a dimensão do quanto isso é perigoso e danoso para as relações sociais é requisito essencial para construirmos relações de gênero mais justas, mais humanas e, portanto, sem violência.

\section{Emicida e a interseccionalidade}

Conforme nos aponta Susan McClary, musicóloga, famosa no meio acadêmico por ser professora de musicologia na Universidade norte-americana Case Western Reserve, combinando a musicologia com críticas feministas, seja para o lado positivo e também para o lado negativo, a música inegavelmente nos socializa.

A música influencia imensamente a formação da identidade dos indivíduos, ensinando a compreender emoções, vontades e até mesmo seus próprios corpos. Grande parte dos estudos relacionados ao universo musical e seu impacto na vida social revelam que a música contribui significativamente na construção de quem somos, inclusive na construção da sexualidade.

Analisar as construções de gênero, poder e sexualidade ligadas ao texto musical assim como aos discursos relacionados ao estudo dos mesmos não é tarefa simples, requer muito cuidado, leitura, visão de mundo diversa e aberta a questionamentos.

Sendo assim, buscar em cada letra de música um discurso impregnado de contexto, cultura, estereótipos, preconceitos torna-se 
imprescindível, como por exemplo a questão da mulher, a posição que ocupa em diversas áreas da vida real, sendo descrita e julgada o tempo todo dentro de um padrão cultural criado dentro do patriarcado, onde sua emoção, sensibilidade, sensualidade, frivolidade, até sua suposta inferioridade a impede de se posicionar e ser reconhecida como alguém capaz de produzir música assim como questionar quando uma letra musical se apropria de maneira inadequada sobre sua representação dentro de um espaço social.

Susan MCclary afirma em sua obra Gênero, música e sexualidade, que entender a razão da misoginia impregnada na musicologia nos permite aprofundar sobre a rede de metáforas criadas que reforçam constantemente nossas ideias de gênero. Historicamente acompanhamos homens brancos, héteros no comando do que pode, como e deve ser produzido no mundo, inclusive na música. A noção e dimensão das chamadas relações de gênero revela-se no Brasil através de instituições estruturadas de forma que não se aprofundam de fato nestas questões do masculino e feminino e o impacto do discurso musical na sociedade. Mesmo a Academia Brasileira de Música e a Sociedade Brasileira de musicologia carecem de pesquisas que problematizem esses pontos, como a forma das mulheres serem vistas nestas letras musicais.

Em Mulheres, Raça e Classe, Davis (2016, p. 109) escreve que depois de séculos de privação educacional, o povo negro passou a reivindicar com o ardor o direito de satisfazer seu profundo desejo de aprender. Segundo a autora, "com frequência, os poderes mistificadores do racismo emanam de sua lógica irracional e confusa. De acordo com a ideologia dominante, a população negra era supostamente incapaz de progressos intelectuais".

Apresentando ideias de Lélia Gonzalez, mulher negra, historiadora e filósofa brasileira que criticava a hierarquização dos saberes como produto da classificação racial da população, Ribeiro (2017, p. 24) nos chama a reconhecermos a equação: “quem possui o privilégio social possui o privilégio epistêmico, uma vez que o modelo 
valorizado e universal de ciência é branco". Seria preciso desestabilizar e transcender a autorização discursiva branca, masculina cis e heteronormativa ${ }^{1}$ e debater como as identidades foram construídas nesses contextos.

Segundo Alcoff (2016), precisamos nos ater à identidade social, não somente para evidenciar como o projeto de colonização tem criado essas identidades, mas para mostrar como certas identidades têm sido historicamente silenciadas e desautorizadas no sentido epistêmico, ao passo que outras serão fortalecidas. bell hooks (2019a) percorre o caminho trilhado por aquelas que estão na margem, sendo que estar na margem é fazer parte do todo, mas fora do corpo principal.

Ribeiro (2017) afirma que tal debate pretende, fundamentalmente entender como poder e identidades funcionam juntos a depender de seus contextos e como o colonialismo, além de criar, deslegitima ou legitima certas identidades. Logo, não é uma política reducionista, mas atenta-se para $o$ fato de que as desigualdades são criadas pelo modo como o poder articula essas identidades; são resultantes de uma estrutura de opressão que privilegia certos grupos em detrimento de outros.

Em erguer a voz: pensar como feminista, pensar como negra, bell hooks (2019b), relata sua experiência como aluna de diferentes universidades estadunidenses. De acordo com a autora, a ideia de que estudantes negros, principalmente estudantes negras, não eram espertos o suficiente para fazer pós-graduação era assumida e a mensagem era transmitida por meio de várias humilhações. É o que Haider (2019, p. 59) denomina microagressão: "formas de racismo sutil e também a paranoia racial decorrente dela". Pela política identitária ser

11 “Uma pessoa cis é uma pessoa na qual o sexo designado ao nascer + sentimento interno/subjetivo de sexo + gênero designado ao nascer + sentimento interno/subjetivo de gênero, estão 'alinhados' ou 'deste mesmo lado' - o prefixo cis em latim significa "deste lado" (e não do outro), uma pessoa cis pode ser tanto cissexual e cisgênera mas nem sempre, porém em geral ambos." Uma pessoa cis é aquela que politicamente mantém um status de privilégio dentro da cisnorma. Ou seja, ela é politicamente vista como "alinhada" dentro de seu corpo e de seu gênero

(GELEDES, 2016). 
frequentemente introduzida aos jovens por acadêmicos que têm uma compreensão parcial da profundidade dela, eles também reproduzem uma confusão.

Ao conquistar o acesso à pós, hooks (2019b) afirma que os estudantes brancos não experienciavam, diariamente, também fora do campus, a degradação, a humilhação. Para eles, tolerar formas de exploração e dominação na pós-graduação não evocava imagens de uma vida inteira de abusos. Além disso, para a autora, o pequeno número de mulheres negras em posições permanentes nas instituições acadêmicas não constitui uma presença significativa forte o suficiente para desafiar vieses racistas e machistas e traz um dado alarmante: mulheres não brancas que trabalham em tempo integral constituem menos de três por cento do total do corpo docente na maior parte dos campi dos Estados Unidos. hooks (2019b), afirma que "racismo e machismo, especialmente no nível da pós-graduação, moldam e influenciam tanto o desempenho acadêmico quanto a empregabilidade de mulheres negras acadêmicas".

Corroborando com a autora, Apple (2017) afirma que a política dos corpos, embutida na materialidade de ambientes físicos, interrompeu a tentativa oficial de cessar a dominação. Para o autor, o modelo de desempenho acadêmico, influenciado cada vez mais fortemente pelas preocupações gerenciais do controle técnico e da eficiência, tem negligenciado o real conteúdo do próprio conhecimento, falhando assim em considerar com seriedade as possíveis conexões entre a economia e a estrutura do conhecimento escolar, atendo-se apenas à defesa da importância da "produção" dos alunos e alunas em uma linha disciplinar muito forte para que também a democracia continue a ser forte, e assim por diante. Palavras de ordem como ordem, segurança, neutralidade, entre outras.

À partir das provocações de beel hooks (2019a), se os homens não são iguais entre si dentro da estrutura de classe patriarcal, capitalista e de supremacia branca, com quais homens as mulheres querem se igualar? O que está implícito nesta definição simplista de 
libertação feminina? Para hooks, "o movimento feminista continua sendo uma das frentes mais poderosas de luta por justiça social no mundo de hoje". A autora defende escritos sobre essa temática que falem para qualquer um, pois, do contrário, a educação feminista para uma consciência crítica não poderá vingar e afirma que movimento ainda não produziu uma revolução sustentável. Não acabou com o patriarcado, não erradicou o seximo nem a exploração e a opressão sexistas. Em consequência, como alerta Beauvoir (1980), nossos ganhos estão sempre em risco.

A interseccionalidade, ferramenta de análise social, conecta dois lados de produção de conhecimento, a saber, a produção intelectual de indivíduos com menos poder, que estão fora do ensino superior, da mídia de instituições similares de produção de conhecimento, e o conhecimento que emana primariamente de instituições cujo propósito é criar saber legitimado. De acordo com Collins (2017), o Coletivo Combahee River, publicou um manifesto chamado Black Feminsit Statement, que propunha que racismo, exploração de classe, patriarcado e homofobia, coletivamente, moldavam a experiência de mulher negra, a libertação das mulheres negras exigia uma resposta que abarcasse os múltiplos sistemas de opressão. Para a autora, ou a liberdade é indivisível e trabalhamos em conjunto por ela ou você estará em busca de seus próprios interesses e eu dos meus.

De acordo com Oliveira e Cuevas (2018), no Brasil, o RAP aparece em 1986 na cidade de São Paulo, logo na Década de 1990 começa a ganhar espaço em rádios e na indústria fonográfica brasileira. Impulsionado em várias partes do Brasil, foi crescendo e

desafiando os preconceitos impostos pela sociedade, que lidava com mudanças, movimentos sociais identitários que se fortaleceram durante os anos 1990, como o Movimento de Mulheres, o Movimento LGBT, o Movimento Negro, Movimento Indígena entre outros. Saindo da periferia para chegar ao grande público, acabou gerando grandes nomes, a maioria masculina, como é o caso de Emicida. 
Emicida tem tido papel relevante nas redes sociais de forma geral, por suas falas representativas e positivas no que se refere a luta contra o racismo e pelo empoderamento da população negra. Em especial, a mulher negra que sofre ainda mais porque além do racismo, enfrenta problemas de classe e gênero.

\section{Deus é uma mulher preta?}

Segundo Collins (2017), campos orientados às políticas públicas têm mostrado uma afinidade especial com a interseccionalidade. A política pública encontra utilidade nas análises interseccionais para entender como os locais sociais interseccionais influenciam escolhas de vida. A trajetória da interseccionalidade aponta para os desafios de avançar políticas emancipatórias em um contexto político e epistêmico da academia neoliberal. O neoliberalismo valoriza a realização individual e a responsabilidade pessoal acima das ideias coletivas relativas ao bem público.

Para bell hooks (2019a, p. 37)

enquanto não for conscientemente traçada a diferença entre uma teoria da individualidade que reconheça a importância do indivíduo dentro da coletividade social e a ideologia do individualismo fundada na competição individual, não há como ter clareza sobre os rumos que se deve tomar para a elaboração de uma teoria feminista da libertação no mundo ocidental.

Afinal, o impacto positivo das reformas liberais na vida das mulheres não deve ser confundido com a erradicação do sistema de dominação.

Como cita Sueli Carneiro, em sua obra, Enegrecer o feminismo:

$\mathrm{O}$ atual movimento de mulheres negras, ao trazer 
para a cena política as contradições resultantes da articulação das variáveis de raça, classe e gênero, promove a síntese das bandeiras de luta historicamente levantadas pelos movimento negro e de mulheres do país, enegrecendo de um lado, as reivindicações das mulheres, tornando-as assim mais representativas do conjunto das mulheres brasileiras, e, por outro lado, promovendo a feminização das propostas e reivindicações do movimento negro.

A liberdade do povo negro só existirá de fato quando atingir homens e mulheres negras de forma igualitária.

Michel Foucault, em seu livro A ordem do discurso, afirmava que a análise do discurso já era em si uma teoria para a luta, que é a resistência do sujeito, aos ditos discursos dominantes, assim como a disputa entre os mesmos, que permite a evolução da cultura e da história.

Para o filósofo sociedades sem transformações simplesmente não existem, uma vez que estão sempre construindo suas próprias referências e até significações. Segundo ele as lutas pelo poder correspondem aos conflitos pela padronização de significados.

Por isso, em a obra A microfísica do poder, defende que apesar de haver um poder central, ele jamais será único, sendo permanentemente cercado por outros poderes. Seleciona-se dessa forma os sujeitos que falam, enquanto outros são impedidos de ter acesso ao discurso e seu real significado.

Nesse processo de controle do discurso determina-se, por exemplo, que para poder falar é preciso ser qualificado, o que automaticamente excluiu grande parcela de indivíduos da possibilidade de expressar o que pensa, padronizam-se até mesmo comportamentos, gestos, que devem ser praticados por um determinado grupo de sujeitos.

Analisando por esse prisma o rap no Brasil percebemos que claramente a presença feminina foi cortada, retirando seu lugar de fala. 
Inclusive para que muitas mulheres conseguissem tomar a palavra foi preciso que se "adequassem" aos rituais masculinos que englobavam o movimento, como, por exemplo, as roupas largas.

Foi preciso que as mulheres usassem seu lugar de fala dentro desse universo machista para conquistarem seu direito de resposta aos raps que as colocavam o tempo todo sem situação inferior e de exposição depreciativa. Rappers mulheres como Lívia Cruz e Lady Rap mostram que conhecem bem o significado do feminismo e sabem lutar por respeito e igualdade de gêneros, que deve trazer como pauta inquestionável a equidade de oportunidades, tantas vezes negadas das mulheres.

Ampliar esses espaços de fala e dar voz a essas mulheres contribui significativamente no combate ao preconceito e a violência contra a mulher, mostrando a preocupação em se buscar a sororidade, que evidencia a luta e resistência dessas mulheres que estão dispostas a enfrentar julgamentos, preconceitos e intolerância para conquistar o lugar que desejarem.

\section{Referências}

ALCOFF, L. M. Uma epistemologia para a próxima revolução. Revista Sociedade e Estado, v. 31, n. 1, p. 129-143, jan./abr. 2016.

APPLE, M. W. A Luta pela democracia na educação crítica. Revista eCurriculum, v. 15, n. 4, p. 894-926, dez. 2017.

COLLINS, P. H. Se perdeu na tradução? Feminismo negro, interseccionalidade e política emancipatória. Parágrafo, v. 5, n. 1, p. 617, jun. 2017.

DAVIS, A. Mulheres, Raça e Classe. São Paulo: Boitempo, 2016.

hooks, b. erguer a voz: pensar como feminista, pensar como negra. São Paulo: elefante, 2019b.

RIBEIRO, D. O que é lugar de fala? Belo Horizonte: Letramento, 2017.

hooks, b. Teoria feminista: da margem ao centro. São Paulo: Perspectiva, 
2019a.

RODRIGUES, E. C. R. Músicas sertanejas: Um diálogo entre raízes e ideologias. Signo, v. 33, v. 54, p. 141-192, 2008.

SAFFIOTI, H. I. B. Gênero, patriarcado, violência. São Paulo: Editora Fundação Perseu Abramo, 2004.

SCHRAIBER, L. B.; OLIVEIRA, A. F. P. L; FRANÇA-JÚNIOR, I.; PINHO, A. A. Violência contra a mulher: estudo em uma unidade de atenção primária à saúde. Revista de Saúde Pública, v. 36, n. 4, p. 470477, 2002.

SILVA, M. A. Músicas que violentam a mulher: Representações Machistas nas letras de forró estilizado. In: Coloquio Nacional Representações de Gênero e Sexualidades, XII., 2016. Anais [...]. Disponível em: http://www.editorarealize.com.br/revistas/conages/trabalhos/TR ABALHO_EV053_MD1_S A3_ID1749_09052016230400.pdf. Acesso em: 05 ago. 2020.

TELES, Maria Amélia de Almeida; MELO, Mônica de. O que é violência contra a mulher. São Paulo: Brasiliense, 2003. (Coleção Primeiros Passos). 